\author{
Military Technical College \\ Kobry El-Kobbah \\ Cairo, Egypt
}

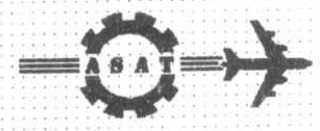

$10^{\text {th }}$ International Conference

On Aerospace Sciences\&.

Aviation Technology

\title{
BALLISTIC EFFICIENCY OF DIFFERENT CERAMIC MATERIALS AGAINST TUNGSTEN ALLOY ROD PENETRATORS
}

\author{
BY
}

A. M. Riad*

\begin{abstract}
In this paper, the analytical model developed by Riad [1] has been modified herein to describe the penetration of a high-speed rod into a ceramic tile backed by a thick metallic plate. The present model identifies three main phases for the target penetration; these are: (i) ceramic fragmentation, (ii) penetration into fragmented ceramic, and (iii) penetration into thick back plate. Phase (i) consists of a single stage, whereas each of the other two phases consists mainly of two penetration stages. Two modes are considered to be associated with the rod and thick back plate during penetration process; these are erosion and rigidity. The main equations representing each penetration stage are introduced. The current penetration stage is ascertained according to the relative velocity between the rod mass and mass of ceramic or thick back plate in contact with the rod front. Moreover, the present model is adapted to describe the penetration of such a rod into thick back plate only by setting the thickness of ceramic tile equal to zero.
\end{abstract}

The present model is capable of predicting the time histories of the velocities of moving masses and the rod penetration depth through ceramic/metal and thick metallic targets, respectively. For the penetration of thick steel plate, the essential dependence of its flow stress on deformation rate is considered. In addition, the matching of predicted results of the present model with the corresponding experimental measurements of Reaugh et al. [2] serves for the determination of the flow stress of ceramic globally. The present results are concerned with the determination of ballistic efficiencies of different ceramic materials based on the predicted residual penetration depth into a thick steel backing. The influence of ceramic strength, thickness and rod impact velocity on the ballistic mass efficiency of ceramic is presented and discussed.

\section{KEY WORDS}

Dynamics, solid mechanics, Impact dynamics, and penetration mechanics

\footnotetext{
* Egyptian Armed Forces
} 


\section{INTRODUCTION}

Research on ceramic materials for armor applications has been performed for over 30 years. The extensive work of Wilkins [3] has been considered as the most comprehensive study in this field. His experimental configuration consisted of bonding a relatively thin ceramic tile to a backup plate and shooting a $7.62 \mathrm{~mm}$ armor-piercing projectile at each target. The backing plates were either metals or fiber-reinforced resins. The efficiency of tested ceramic tile was determined in terms of the ballistic limit velocity, defined as the impact velocity at which half of the projectiles do not penetrate the target.

Rosenberg and Yeshurun [4] suggested a recent technique for the determination of the ballistic efficiency of ceramics against armor-piercing projectiles. This technique was based on supporting the ceramic tile with a very thick metal and measuring the penetration depth of projectile into this backing. Their experimental program showed that the ballistic efficiencies of the different ceramic tiles increased with their normalized effective compressive strength; this strength was defined as the average of static and dynamic compressive strengths divided by the density of the ceramic. Woodward et al. [5] deduced similar results to those obtained by Rosenberg and Yeshurun for soft ceramics; however, the ballistic efficiencies of hard ceramics were found to be unrelated to their compressive strengths. They argued that the hard ceramics were used to break the projectile noses and create inefficient penetrators that resulted in similar residual penetration depths in metallic backing.

Rosenberg and Tsaliah [6] studied the application of Tate's model for the interaction of long rods with ceramic targets. They conducted an experimental program to determine the strength factors of different thick ceramic tiles. Moreover, They performed a series of tests by impacting long rods of different materials into thin tiles of ceramic materials bonded to thick steel plates. They compared their experimental measurements with the predictions of Tate's model using the values of strength factors determined by their thick tile experiments; good agreement was obtained. Finally, they recommended the use of Tate's model for rod-ceramic combination considering the ratio of ceramic strength factor to its Hugoniot elastic limit about 1.

Woodward [7] modeled the projectile penetration into a ceramic tile backed by thin and thick metallic plates, respectively. He used the momentum conservation principle to derive the main equations representing the model. He fitted the experimental data of Wilkins [3] to the predicted results of his model to determine the flow stress of AD85 ceramic. He recommended that: (i) the flow stress of ceramic be represented by its hardness divided by a factor; this factor varies from 1 to 2.9 , and (ii) the flow stress of ceramic increase with its thickness.

Orphal and Franzen [8] performed a series of experiments to measure the penetration of long tungsten rods into confined silicon carbide ceramic targets. They used penetrators having an aspect ratio of 30 , their impact velocities ranged from 1.5 to $4.6 \mathrm{~km} / \mathrm{s}$. Each target was a simple cylinder of silicon carbide ceramic with a thickness such that it would effectively be semi-infinite in depth. The penetrator/target interaction during the penetration event was photographed using $X$ rays. They determined the time histories of the penetration depth and penetrator remaining length, respectively. They concluded that: (i) the obtained results were confirmed with those of the hydrodynamic penetration theory, (ii) the target strength term of Tate's model could be determined for silicon carbide ceramic using the obtained experimental data, and (iii) the ballistic efficiency of such a ceramic decreased with increasing the impact velocity. Similar results were obtained by Orphal et al. [9] who performed a series of experiments to measure the penetration of the same rods into boron carbide ceramic targets. They also found that the ballistic efficiency of boron carbide ceramic was greater than that of aluminum nitride and silicon carbide ceramics, respectively, over the impact velocity range used. 
An extensive experimental study was conducted by Rosenberg et al. [10] to quantify the ballistic efficiency of confined AD85 alumina tiles. Their experiments included scaled long rods made of tungsten alloy, with aspect ratios of 10 and 12.5 and diameters of 5 and $5.8 \mathrm{~mm}$, respectively. Impact velocities of rods ranged from 1.25 to $3 \mathrm{~km} / \mathrm{s}$ and tile thicknesses were varied between 10 and $80 \mathrm{~mm}$. Each tile was glued to thick hard steel backing, in which the residual penetration depth was measured. They found that: (i) the ratio of penetration depth into steel backing divided by ceramic thickness was constant for the used range of tile thickness and impact velocity, and (ii) this ratio was 1.7 compared with the strong steel backing and was probably much closer to 2 , if compared with the standard RHA steel.

Reaugh et al. [2] determined the ballistic efficiency of five ceramic materials when thick steel plates backed them. Their tested ceramics were alumina, silicon carbide, boron carbide, aluminum nitride and titanium diboride. They used tungsten alloy rods with a diameter of 6.35 $\mathrm{mm}$ and an aspect ratio of 4 ; these were fired at velocities ranging from 1.35 to $2.65 \mathrm{~km} / \mathrm{s}$. They de minimum areal density of each ceramic material needed to keep the rod from penetrating the backup steel. They deduced that: (i) the ballistic efficiency of each tested ceramic material increased approximately linear with impact velocity, and (ii) the rate of in efficiency was lower for aluminum nitride than the other tested ceramics.

In the following, an analytical model has been presented to describe the penetration of a highspeed rod into a ceramic tile backed by a thick metallic plate. Two modes are considered to be associated with the rod and thick metallic plate during penetration process; these are erosion and rigidity. In addition, the penetration process in ceramic/metal target is considered to consist

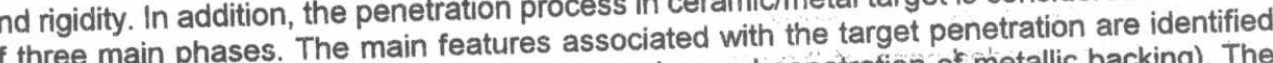
(ceramic erosion, ceramic conoid formation, erosion and penetration of metallic backing). The compiled into a main equations representing the prosent computer program. The input data to the computer progras into a thick metallic plate. model is also capable of describing the rod penetration process into a thick

For the penetration of a thick metallic plate, the essential dependence of its flow stress on deformation rate is considered. For ceramic/metal target, comparison of the predicted results with the corresponding experimental results of other investigators leads to the determination of the global strengths, thicknesses and rod impact velocity on their ballistic efficiencies are presented and discussed.

\section{ANALYTICAL MODEL}

In this model, the projectile is idealized as a cylindrical rod of initial length $L_{0}$ and initial diameter Similar to the one-dimensional models developed by Tate $[11,12]$ and Alekseevskii [13], the rod material is assumed to behave as rigid-perfectly plastic with respect to its nominal stress-

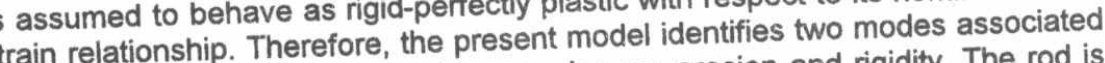
with the penetrating rod through the target; these modes are erosion and rigidity. The rod is assumed to strike the target normally with a high-speed velocity. For oblique impact, the rod the element is assumed to represent the thickness of this element. The present model considers the target to consist of a ceramic tile of thickness $\mathrm{H}_{\mathrm{co}}$ backed by a thick metallic plate. As mentioned before, the model divides the pentation, (ii) penetration of target into three main phases; these are: (i) ceramic plate. The phase (i) consists of one fragmented ceramic, and (iii) penetration of thick mists of two penetration stages. The material stage, whereas each of the other two phases consists to rod material for the nominal stressof thick metallic plate is assumed engineering strain relationship. 
The present model is based on equating the pressure at the rod-target interface. The main equations representing each penetration stage are introduced. The sequence of penetration stages depends on the relative velocities between mass of rod rigid part and mass of the remaining fragmented ceramic or mass of thick metallic plate in contact with the rod front. The different sequences of penetration stages that represent the complete penetration process of a rod into a ceramic tile backed by a thick metallic plate are shown in Fig. 1.

For each penetration stage, a system of first order dependent differential equations has been presented. The penetration time is taken as the independent variable and the system is solved numerically. The end conditions of the current stage are considered as the initial conditions for the subsequent stage. The system solution gives the velocity of rod rigid part, the penetration velocity, the rod penetration depth and the interface pressure as functions of time. The penetration process terminates when the rod stops inside the target, i.e. it attains zero velocity.

In the following, the physical concepts considered and the main assumptions adapted for modeling the rod penetration into a ceramic tile backed by a thick metallic plate are presented. The main equations representing each penetration stage are listed in Table 1.

\section{Physical Concepts and Main Assumptions}

Physical concepts and assumptions introduced in Ref. [1] for the ceramic fragmentation phase (cf. Fig. 2a) are considered. Main assumiptions for the penetration of fragmented ceramic phase (cf. Fig. $2 \mathrm{~b}$ and $2 \mathrm{c}$ ) presented in Ref. [1] are also considered in addition to:

- The eroded zone of the rod and ceramic ahead of the rod is assumed to have the current penetration velocity $U$, whereas the remaining ceramic and the thick metallic backing are assumed to be stationary.

The main assumptions considered for the Penetration of thick back plate phase (cf. Fig 2d) are: - The remaining rod alone penetrates the thick metallic plate. The rod mode may be changed from erosion to rigid.

- The surface of thick metallic plate ahead of the rod is subjected to erosion and forms a crater. The mass of plate material around the crater is assumed to be stationary.

- The erosion process of back plate surface continues until the rod penetration velocity vanishes, i.e. when the rod stops inside the thick metallic plate.

The main equations representing the different phases of the present model are compiled into a computer program. This program can be adopted to describe and predict the parameters associated with the rod penetration into a ceramic/metal target or a thick metallic plate. For a ceramic/metal target, the predicted residual penetration depth into a thick metallic backing evaluates the ballistic efficiency of a ceramic, and weight saving compared with the rod penetration depth into thick metallic plate only. Moreover, the present model is capable of predicting the limit ballistic efficiency of each cerarnic type. The relative difference for any parameter represents the ratio of absolute difference between predicted and measured values of such a parameter divided by its measured value in percent.

\section{RESULTS AND DISCUSSIONS}

In the following, results of the present model are classified into: (i) model validation, and (ii) predictions. These predictions are concerned with the determination of ballistic efficiencies of different ceramic materials based on the predicted residual penetration depth into a thick steel backing. Moreover, the influence of ceramic strength, thickness and rod impact velocity on its ballistic efficiency and weight saving is presented and discussed. 
Table 1. Main equations representing each phase of the present model.

\section{1- The following equation holds for the three phases:}

* Time rate of change of rod penetration depth Z:

$$
\frac{d Z}{d t}=U,
$$

U: current penetration velocity.

II- For eroding rod, the following equations hold for the three phases:

* Time rate of change of length of rod rigid part:

$$
\frac{d L}{d t}=-(V-U) \text {, }
$$

$\mathrm{L}$ : current length of rod rigid part, V: current velocity of rod rigid part.

* Deceleration of rod rigid part during penetration:

$$
\frac{d V}{d t}=-\frac{Y_{p}}{\rho_{p} L},
$$

$Y_{p}$ : flow stress of rod material, $\rho_{p}$ : density of rod material.

\section{III- Phase (i): Ceramic fragmentation:}

* Pressure at rod-ceramic interface, $P_{i}[14]$ :

$$
P_{1}=Y_{p}+\frac{1}{2} \rho_{p}(V-U)^{2}=Y_{c o}+\frac{1}{2} \rho_{c} U^{2},
$$

$Y_{\text {co: }}$ flow stress of intact ceramic, $\rho_{c}$ : density of ceramic material.

* Current penetration velocity $\mathrm{U}$ as a function of velocity of rod rigid part $\mathrm{V}$ :

$$
U=\frac{V-\sqrt{\mu V^{2}+(1-\mu) A}}{(1-\mu)},
$$

where

$$
\mu=\frac{\rho_{c}}{\rho_{p}},
$$

and

$$
A=\frac{2\left(Y_{c o}-Y_{p}\right)}{\rho_{p}} .
$$

* End condition:

$$
\mathrm{Z}+\mathrm{S}_{\text {crack }}=\mathrm{H}_{\text {co }},
$$

where

$$
\mathrm{S}_{\text {crack }}=\mathrm{V}_{\text {crack }} \cdot \mathrm{t}
$$


Table 1. Main equations representing each phase of the present model (continued).

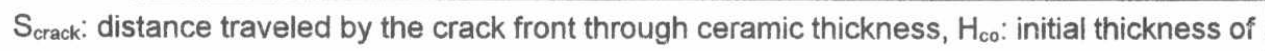

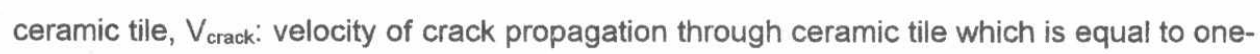
fifth the value of longitudinal velocity of stress wave through ceramic material [15], $t$ : penetration time.

\section{IV- Phase Il: Penetration into fragmented ceramic:}

Stage (1): Penetration of eroding rod into fragmented ceramic, $\left(V>U>0\right.$, and $\left.Z<H_{c o}\right)$ :

* Pressure at rod-ceramic interface, $P_{\mathrm{i}}[14]$ :

$$
P_{1}=Y_{p}+\frac{1}{2} \rho_{p}(V-U)^{2}=Y_{c}+\frac{1}{2} \rho_{c} U^{2},
$$

$\mathrm{Y}_{\mathrm{c}}$ : flow stress of fragmented ceramic.

* Current flow stress of fragmented ceramic given by:

$$
\mathrm{Y}_{\mathrm{c}}=\mathrm{Y}_{\mathrm{co}}\left[\frac{\mathrm{V}}{\mathrm{V}_{\mathrm{s} 1}}\right]^{2},
$$

$V_{s 1}$ : velocity of rod rigid part when ceramic fragmentation phase terminates.

* Current penetration velocity $U$ as a function of velocity of rod rigid part $V$ :

where

$$
U=\frac{V-\sqrt{\mu V^{2}+(1-\mu) A_{c}}}{(1-\mu)}
$$

$$
A_{c}=\frac{2\left(Y_{c}-Y_{p}\right)}{\rho_{p}} .
$$

* Time rate of change of fragmented ceramic thickness:

$$
\frac{d H_{c}}{d t}=-U
$$

$\mathrm{H}_{c}$ : current thickness of fragmented ceramic.

* End conditions:

$$
\begin{aligned}
& \text { (i) } \mathrm{Z}=\mathrm{H}_{\mathrm{co}} \text {, or } \mathrm{V}=\mathrm{U} \succ 0.0 \text {. } \\
& \text { (ii) } \mathrm{U}=\mathbf{0 . 0} \text {, penetration stops. }
\end{aligned}
$$

Stage (2): Rigid rod penetration into fragmented ceramic, $\left(V=U>0\right.$, and $\left.Z<H_{c o}\right)$ :

* Pressure at rod-ceramic interface, $P_{i}[14]$ :

$$
P_{1}=Y_{p}=Y_{c}+\frac{1}{2} \rho_{c} V^{2},
$$

$Y_{c}$ is calculated by Eqn. (8) 
Table 1. Main equations representing each phase of the present model (continued).

* Deceleration of rigid rod during penetration:

$$
\frac{d V}{d t}=-\frac{Y_{p}}{\rho_{p} L_{r}},
$$

$L_{r}$ : length of rigid part of rod when its erosion terminates.

* Time rate of change of fragmented ceramic thickness, Eqn. (10).

* End Condition:

(i) $\mathrm{Z}=\mathrm{H}_{\text {co }}$.

(ii) $\mathrm{V}=\mathbf{0} .0$, penetration stops.

V- Phase III: Rod penetration into thick metallic plate:

Stage (1): Back plate penetration by eroding rod, $(\mathrm{V}>\mathrm{U}>0)$ :

* Pressure at rod-back plate interface, $\mathrm{P}_{\mathrm{i}}$ :

$$
P_{1}=Y_{p}+\frac{1}{2} P_{p}(V-U)^{2}=Y_{B}+\frac{1}{2} \rho_{B} U^{2},
$$

$Y_{B}$ : flow stress of back plate material, $\rho_{c}$ : density of back plate material.

* Current penetration velocity $U$ as a function of velocity of rod rigid part $V$ :

$$
U=\frac{V-\sqrt{\mu_{B} V^{2}+\left(1-\mu_{B}\right) A_{B}}}{\left(1-\mu_{B}\right)},
$$

where

$$
\mu_{B}=\frac{\rho_{B}}{\rho_{P}}
$$

and

$$
A_{B}=\frac{2\left(Y_{B}-Y_{p}\right)}{\rho_{p}} .
$$

* End condition:

$$
\mathbf{V}=\mathbf{U} \succ \mathbf{0 . 0}
$$

Stage (2): Rigid rod penetration into thick back plate, $(V=U>0)$ :

* Pressure at rod-back plate interface, $P_{i}$ :

$$
P_{1}=Y_{p}=Y_{B}+\frac{1}{2} \rho_{B} V^{2},
$$

* Deceleration of rigid rod during penetration:

$$
\frac{d V}{d t}=-\frac{Y_{p}}{\rho_{p} L_{r}} .
$$

* End Condition:

$$
\mathbf{U}=\mathbf{V}=\mathbf{0} \text {. }
$$


Table 1. Main equations representing each phase of the present model (continued).

* Finally, after determining the final depth of penetration into ceramic/thick back plate target, the following are determined:

- The ballistic efficiency of a ceramic, $E_{m}$ :

$$
E_{m}=\frac{\rho_{\mathrm{st}}\left(Z_{\mathrm{st}}-Z_{\mathrm{res}}\right)}{\rho_{\mathrm{c}} \mathrm{H}_{\mathrm{co}}}
$$

$\rho_{\text {St: }}$ density of reference steel, $Z_{\text {st }}$ : depth of rod penetration in reference steel target, $Z_{\text {res: }}$ : residual penetration depth into thick plate that backs the ceramic tile.

- The limit ballistic efficiency of a ceramic tile, $\eta_{m}$ :

$$
\eta_{m}=\frac{\rho_{\text {st }} Z_{s t}}{\rho_{c} H_{c o}{ }^{*}},
$$

$\mathrm{H}_{\mathrm{co}}$ : cerarnic thickness at which no penetration in thick back plate occurs.

- The percent in weight saving due to the use of ceramic tile in front of thick steel plate, $\mathrm{W}$ :

$$
\mathbf{W}=\left(1-\frac{\rho_{\mathrm{c}} \mathrm{H}_{\mathrm{co}}+\rho_{\mathrm{st}} Z_{\mathrm{res}}}{\rho_{\mathrm{st}} Z_{\mathrm{st}}}\right) 100 \%
$$

\section{(i) Model Validation}

* For the penetration of a thick steel target by a tungsten alloy rod The present model is validated by comparing its predicted penetration depths with the corresponding experimental measurements of Reaugh et al. [2] due to the impact of a tungsten alloy rod with different velocities into a $\mathbf{4 3 4 0}$ thick steel target. The input data to the computer program for the materials of rod and steel target, respectively, are listed in Table 2 . The dynamic yield strength of rod and thick steel target materials, respectively, are determined as function of their Brinell hardness number [16]. The flow stress of rod material, $Y_{p}$, is equal to its dynamic yield strength multiplied by a factor of 1.7. However, the flow stress of thick steel target is taken to be dependent on the rate of its deformation [17]. Therefore, the target flow stress, $Y_{B}$, is represented by:

where

$$
Y_{B}=C_{t} \sigma_{y t}{ }^{D} \text {, }
$$

$$
c_{t}=a+b V_{i}
$$

$\mathrm{C}_{t}$ is target flow stress multiplier which is a function of impact velocity, $\sigma_{y t}{ }^{D}$ is the dynamic yield strength of target material, $a, b$ are coefficients, and $V_{i}$ is the rod impact velocity.

At each impact velocity, the matching between the predicted depth of penetration and the corresponding experimental measurement of Reaugh et al. serves to predict the value of the multiplier $\mathrm{C}_{\mathrm{t}}$. By fitting Eqn. (25) with the values of predicted multipliers, the values of the 
coefficients $a$, and $b$ are 4.487 and $-14 E-4$, respectively. Table 3 lists the values of measured penetration depth of Ref. [2] and the corresponding predicted depth at each impact velocity.

* For the penetration of a ceramic/metal target by a tungsten alloy rod

The present model is also validated by comparing its predicted penetration depths, due to the normal and oblique impact of a set of ceramic/steel targets with a tungsten alloy rod at different velocities, with the corresponding experimental measurements of Ref. [2]. Reaugh et al. investigated experimentally the impact of a tungsten alloy rod into six types of ceramic, each backed by a 4340 thick steel plate. Foe each type of ceramic, they determined the residual penetration depth into thick steel plate at each impact velocity. The input data to the computer program for each type of ceramic are listed in Table 4.

Initially, the flow stress of each ceramic type is represented by its static compressive strength. The predicted penetration depths are generally greater than the corresponding experimental values of Ref. [2]. The method used by Woodward [7] to determine the flow stress of ceramic is used herein. Therefore, the matching of predicted penetration depths of the present model with the corresponding experimental measurements of Reaugh et al. for each type of ceramic determines the global value of its flow stress. This value is considered to be constant with the thickness of each ceramic type.

By comparing the flow stress of each ceramic type with its Hougniot Elastic limit (HEL), it is found that the flow stress $Y_{c o}$ can be represented by:

$$
Y_{c o}=(0.642 \pm 0.016) * H E L \text {. }
$$

The predicted residual penetration depths into thick steel plate backed each type of ceramic at different impact velocities and the corresponding experimental measurements of Reaugh et al. are listed in Table 5. Moreover, the predicted total penetration depths into ceramic/metal targets, ballistic efficiencies of ceramic tiles, the corresponding measured values of Ref. [2], and their absolute relative differences, respectively, are listed in the same table. The maximum absolute relative difference between the predicted total penetration depth and the corresponding experimental measurement of Ref. [2] is found to be $11.2 \%$ when the rod impacts a $7.8 \mathrm{~mm}$-thick $T_{i} B_{2}$ ceramic tile backed by a 4340 thick steel plate at $V_{i}=1800 \mathrm{~m} / \mathrm{s}$. In addition, The maximum absolute relative difference between the calculated ballistic efficiency based on the predicted and measured residual penetration depths, respectively, is found to be $14.4 \%$ when the rod impacts a $22.1 \mathrm{~mm}$-thick AD85 ceramic backed by a 4340 thick steel plate at $V_{1}=1350 \mathrm{~m} / \mathrm{s}$.

The present model is also used to predict the limit thickness for each ceramic type at which no penetration to the thick back plate occurs; this thickness is denoted by $\mathrm{H}_{\mathrm{c}}{ }^{*}$. A linear regression fit of the residual penetration depth as a function of thickness for each ceramic type at each average impact velocity is done. This fit is extrapolated to determine the value of $\mathrm{H}_{\mathrm{c}}$. The linear $^{*}$ regression equation used is:

$$
\mathbf{Z}_{\text {res }}=\mathbf{A}-\mathbf{B}^{*} \mathbf{H}_{\mathrm{co}} \text {, }
$$

where $A$ and $B$ are constants. The same procedures are applied on the experimental measurements of Reaugh et al. For each type of ceramic, Table 6 lists the values of constants $A_{m}$ and $B_{m}$ based on the experimental measurements of Ref. [2], the corresponding constant values $A_{p}$ and $B_{p}$ based on model predictions, the obtained limit thicknesses based on measured and predicted residual penetration depths, and their absolute relative difference at each average impact velocity. The maximum absolute relative difference is found to be $14.3 \%$ for $\mathrm{TiB}_{2}$ ceramic at average impact velocity of $1347 \mathrm{~m} / \mathrm{s}$. The previous validations prove the predictive capabilities of the present model. 
Table 2. Input data of tungsten alloy rod and thick steel plate to the computer program [2].

\begin{tabular}{|l|c|c|}
\hline \multicolumn{1}{|c|}{ Parameter } & Rod & Sted plate \\
\hline - Brinell hardness number, $[\mathrm{HB}]$ & 300 & 325 \\
\hline - Ultimate strength, $[\mathrm{MPa}]$ & 950 & 1050 \\
\hline - Density of material, $\left[\mathrm{kg} / \mathrm{m}^{3}\right]$ & 18360 & 7850 \\
\hline - Rod length, $\mathrm{L}_{0}[\mathrm{~mm}]$ & 25.4 & - \\
\hline - Rod diameter. D [mm] & 6.35 & - \\
\hline
\end{tabular}

Table 3. Measured penetration depths [2] and corresponding predictions due to the impact of a tungsten alloy rod into a $\mathbf{4 3 4 0}$ thick steel target at different velocities.

\begin{tabular}{|c|c|c|c|c|c|c|c|}
\hline $\begin{array}{l}\text { Ser. } \\
\text { No. }\end{array}$ & Target & 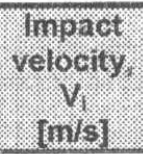 & $\begin{array}{l}\text { Impact } \\
\text { angle, }\end{array}$ & $\begin{array}{l}\text { Measured } \\
\text { depth }[2] \text {; }\end{array}$ & $\begin{array}{l}\text { Average } \\
\text { measured } \\
\text { depth, } \\
\text { [mm? }\end{array}$ & $\begin{array}{l}\text { flow } \\
\text { stress } \\
\text { multiplier? } \\
\text { C }\end{array}$ & $\begin{array}{l}\text { Predicted } \\
\text { Depthi: } \\
\text { : }\end{array}$ \\
\hline 1 & \multirow{7}{*}{ St. 4340} & 1340 & \multirow{7}{*}{0.0} & 26.8 & \multirow{3}{*}{$26.9 \pm 0.1$} & \multirow{3}{*}{2.6} & \multirow{3}{*}{27.04} \\
\hline 2 & & 1340 & & 27.0 & & & \\
\hline 3 & & 1340 & & 27.0 & & & \\
\hline 4 & & 1350 & & 27.8 & $28.15 \pm$ & 26 & 2723 \\
\hline 5 & & 1350 & & 28.5 & 0.35 & 2.6 & 27.23 \\
\hline 6 & & 1740 & & 35.3 & 35.3 & 2.05 & 35.4 \\
\hline 7 & & 1770 & & 36.0 & 36.0 & 2.0 & 35.9 \\
\hline
\end{tabular}

Table 4. Input data of ceramic properties to computer program $[2,4]$.

\begin{tabular}{|c|c|c|c|c|c|c|c|}
\hline $\begin{array}{l}\text { Ceramic } \\
\text { corde }\end{array}$ & $\begin{array}{l}\text { Ceramio } \\
\text { type }\end{array}$ & 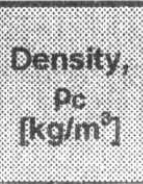 & $\begin{array}{l}\text { Sound } \\
\text { speed } \\
\text { [Mis] }\end{array}$ & $\begin{array}{l}\text { Static } \\
\text { Strength. } \\
\text { comp: } \\
\text { copal }\end{array}$ & 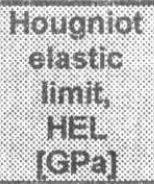 & $\begin{array}{l}\text { Moduius } \\
\text { elasticity. } \\
\text { (EPa) }\end{array}$ & $\begin{array}{l}\text { Ceranic } \\
\text { flow } \\
\text { stross: } \\
\text { yol }\end{array}$ \\
\hline 1 & AD85 & 3420 & 8800 & 2.6 & 6.0 & 224 & 3.95 \\
\hline 2 & AD96 & 3740 & 10100 & 3.0 & 6.5 & 310 & 4.25 \\
\hline 3 & $\mathrm{~B}_{4} \mathrm{C}$ & 2510 & 14200 & 3.9 & 7.0 & 485 & 4.40 \\
\hline 4 & $\mathrm{SiC}$ & 3310 & 12140 & 7.4 & 7.7 & 404 & 4.85 \\
\hline 5 & $\overline{\mathrm{AlN}}$ & 3300 & 10700 & 2.8 & 8.0 & 350 & 5.10 \\
\hline 6 & $\mathrm{Ti} \mathrm{B}_{2}$ & 4460 & 11260 & 6.8 & 11.8 & 414 & 7.60 \\
\hline
\end{tabular}

\section{(ii) Predictions}

Figure 3 plots the predicted ballistic efficiency of each ceramic type with thickness of $10 \mathrm{~mm}$ at different impact velocities. For each impact velocity, it is seen from the figure that the ballistic efficiency increases with the flow stress of ceramic except for $\mathrm{B}_{4} \mathrm{C}$ type. The $\mathrm{B}_{4} \mathrm{C}$ ceramic has a higher efficiency than that of SiC type; however its flow stress is lower than that of SiC ceramic type. This may be attributed to the density of $\mathrm{B}_{4} \mathrm{C}$ ceramic that is lower than that of the $\mathrm{SiC}$ type. Moreover, the ballistic efficiency of each ceramic type increases with impact velocity. This 


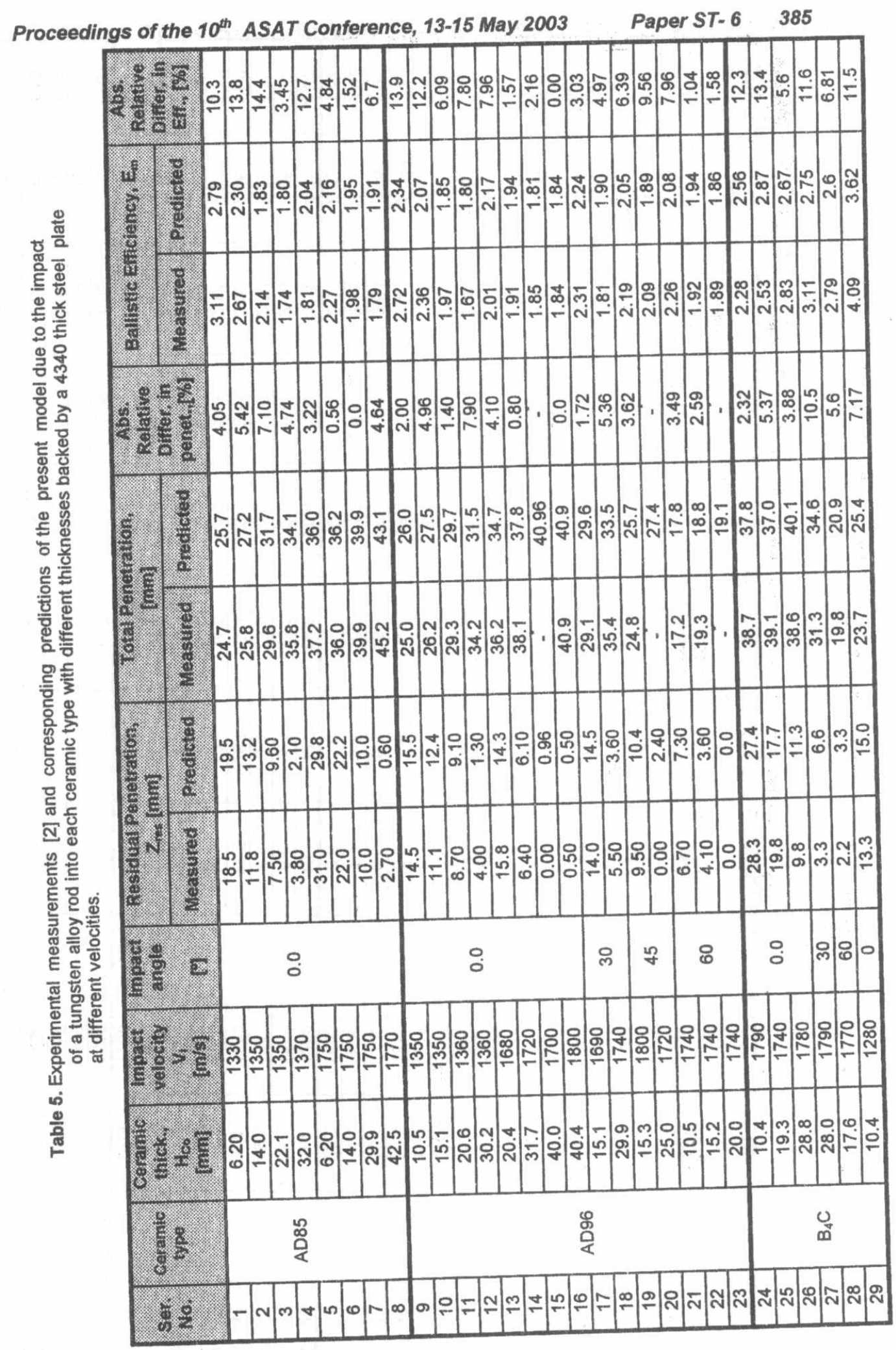




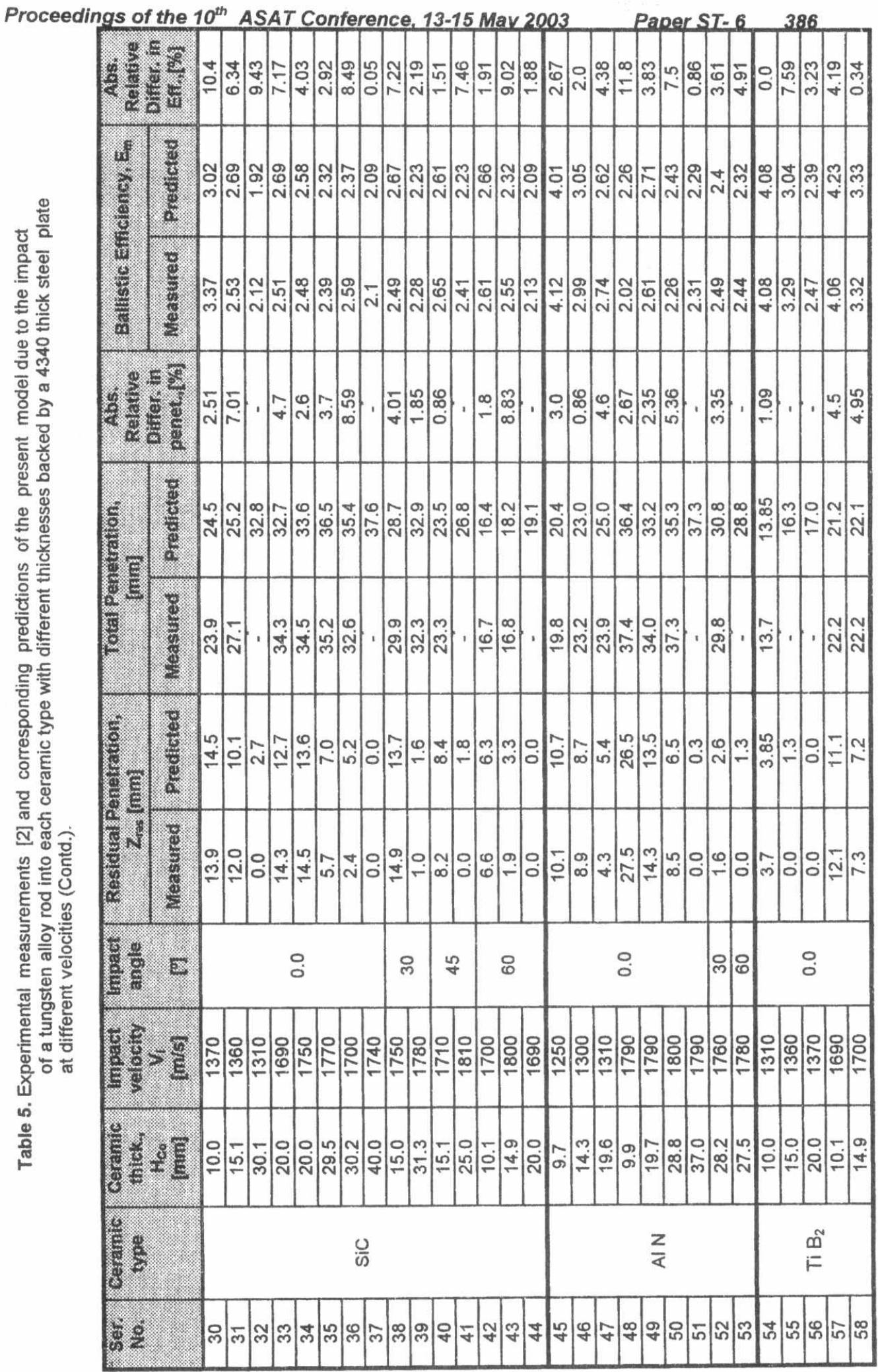




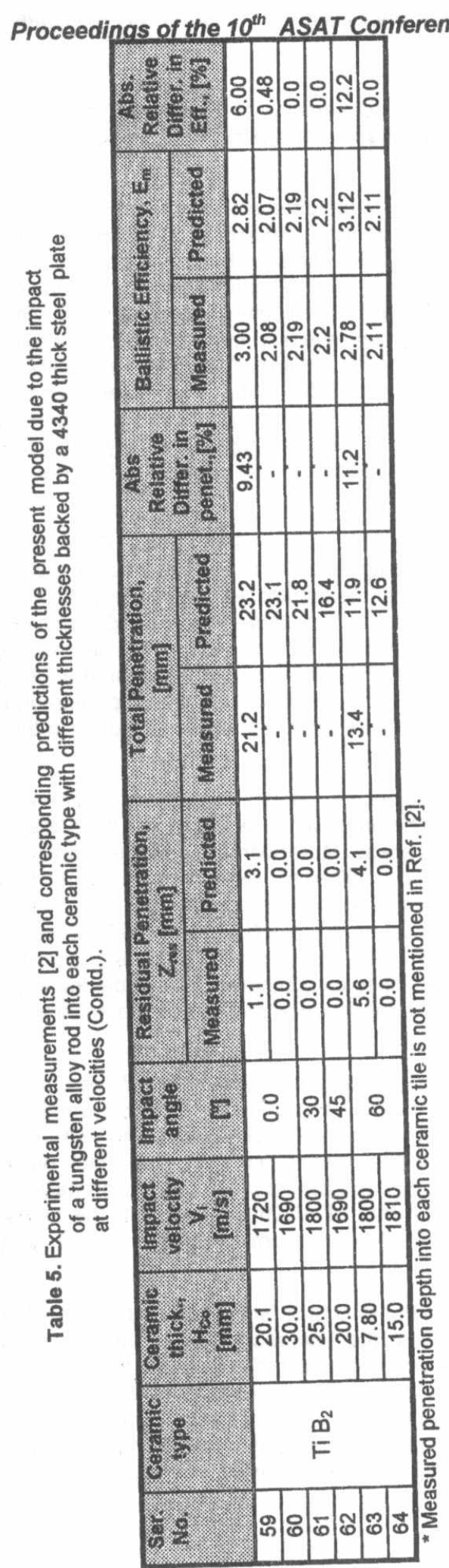

Paper ST- $6 \quad 387$

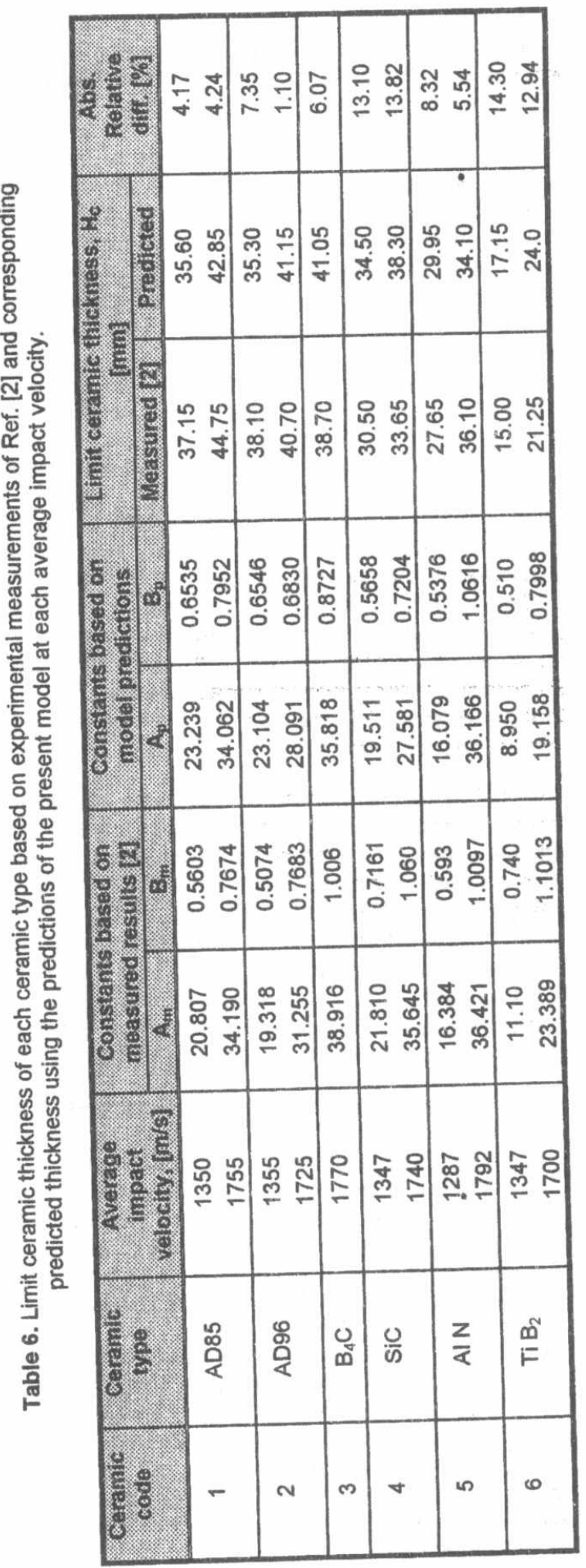


is due to increase of the difference of $\left(Z_{S t}-Z_{\text {res }}\right)$ with impact velocity, cf. Eqn. (21). Therefore, each ceramic type exerts its highest resistance to penetration at the highest impact velocity considered.

Figure 4 shows the predicted change of ballistic efficiency for different thicknesses of AD85 ceramic with impact velocity. For each thickness, the ballistic efficiency of AD85 ceramic increases with impact velocity. For $V_{i}>1800 \mathrm{~m} / \mathrm{s}$. This ballistic efficiency begins to decrease for the highest thicknesses of AD85 ceramic with increasing impact velocity. This may be due to decrease of the difference of $\left(Z_{S t}-Z_{r e s}\right)$ with increasing impact velocity. The ceramic tile with highest thickness cannot withstand he rod penetration, which results in more penetration depth into thick steel back plate at the highest impact velocity considered. Moreover, the ballistic efficiency of $10 \mathrm{~mm}$-thick AD85 ceramic is greater than that of the other thicknesses over the impact velocity range of $1300-1800 \mathrm{~m} / \mathrm{s}$. Therefore, it is recommend to use the $10 \mathrm{~mm}$-thick AD85 ceramic to face the thick steel plate at this particular range of impact velocity. Figure 5 plots similar trends for the predicted change of ballistic efficiency of $\mathrm{Ti}_{\mathrm{B}}$ ceramic, with different thicknesses, with impact velocity as that of AD85 ceramic.

Figure 6 plots the predicted change of ballistic efficiency of 20 mm-thick AD85 and Ti $B_{2}$ ceramic types, respectively, with impact velocity. It is seen from the figure that the ballistic efficiency of Ti $B_{2}$ ceramic is always greater than that of AD85 ceramic over the impact velocity range of 1200 to $2000 \mathrm{~m} / \mathrm{s}$. This is due to the high flow stress of Ti $B_{2}$ ceramic, which decreases the rod capability to penetrate deeper into thick steel back plate, compared to its penetration into AD85 ceramic at each impact velocity. However, the ballistic efficiency of AD85 ceramic is greater than that of Ti $B_{2}$ ceramic at the smallest impact velocity. This is because the rod is not capable of penetrating both $A D 85$ and $T i B_{2}$ ceramic tiles, respectively, at this velocity and the ballistic efficiency in this case is indirectly proportional to the density of ceramic material.

Figure 7 shows the predicted change of ballistic efficiency of AD96 ceramic with different thicknesses at different impact velocities, respectively. The present figure shows that the ballistic efficiency always decreases with increasing ceramic thickness. Moreover, the change of ballistic efficiency with ceramic thickness at $V_{i}=1200 \mathrm{~m} / \mathrm{s}$ has a different trend. This is due to the change of penetration phase for $\mathrm{H}_{\mathrm{C}_{0}}=30 \mathrm{~mm}$ at the end of its penetration process. Moreover, Figure 8 plots the predicted change of the ballistic efficiency of AI N ceramic with different thicknesses at different impact velocities, respectively. Similar trends for the change of ballistic efficiency with ceramic thickness at different impact velocities are obtained. This is because no change of penetration phases representing the complete penetration process for each ceramic thickness at different impact velocities has taken place.

Figure 9 plots the change of ballistic efficiency with thicknesses of AD96 and AI N ceramics, respectively, at $V_{i}=1600 \mathrm{~m} / \mathrm{s}$. This figure shows that the ballistic efficiency of AI N ceramic is generally greater than that of AD96 ceramic over the considered thicknesses. The high flow stress of Al $\mathrm{N}$ ceramic does not allow the rod to penetrate deeper into thick steel back plate compared with its penetration into AD96 ceramic. The present model predicts that the ballistic efficiency of $10 \mathrm{~mm}$-thick AI N ceramic is greater than that of AD96 ceramic with the same thickness by $50.4 \%$. However, the efficiency of $40 \mathrm{~mm}$-thick AI N ceramic is greater than that of the corresponding AD96 ceramic thickness by $12.6 \%$.

Figure 10 plots the predicted residual penetration depth into a thick steel plate backing AD96 ceramic tile of different thicknesses at different impact velocities, respectively. It is seen form the figure that the residual penetration depth decreases with increasing the ceramic thickness at each impact velocity. In addition, the slope of $Z_{\text {res }} / H_{C_{0}}$ is constant for each considered impact velocity. This means that the ratio of $\mathrm{Z}_{\mathrm{res}} / \mathrm{H}_{\mathrm{C}_{0}}$ is independent of impact velocity and ceramic thickness. This result is similar to that obtained by Rosenberg et al. [10] for the alumina class of ceramic. However, this slope is not constant for SiC ceramic at each impact velocity considered, as shown in Fig. 11. 
Figure 12 shows the predicted change of limit ceramic thickness for each ceramic type at different impact velocities, respectively. It is seen from the figure that the limit thickness of each ceramic type increases with impact velocity. Moreover, the limit thickness of each ceramic type decreases with increasing flow stress of ceramic except for $B_{4} C$ ceramic at $V_{1} \geq 1200 \mathrm{~m} / \mathrm{s}$. This is due to the difficulty of penetration high strength ceramic. In addition, the high value of limit thickness of $\mathrm{B}_{4} \mathrm{C}$ ceramic compared with that of $A D 96$ at each impact velocity is questionable.

In general, the residual penetration depth into a thick steel plate backing a ceramic tile increases with impact velocity. The value of this penetration depth is essentially based on the flow stress of a ceramic material. Moreover, this depth decreases with increasing thickness of ceramic tile at the same impact velocity. The percent of mass saving for a ceramic/metal target compared with a metallic target only is dependent on thickness of ceramic tile, residual penetration depth in metallic back plate, penetration depth in thick metallic plate only, and the densities of ceramic and metallic plate materials, respectively, cf. Eqn. (23).

Figure 13 plots the change of mass saving in percent with impact velocity for the considered thicknesses of AD85 ceramic tiles facing a 4340 thick steel plate, respectively. However, there exist trends for the changes of residual penetration depth into thick steel back plate with ceramic thickness and impact velocity, respectively; the changes of mass saving in percent do not have similar trends as that of residual penetration depth or constant trends with impact velocity for the different thicknesses of AD85 ceramic tiles. The present model could predict the preferable thickness of ceramic tile at each impact velocity that gives the greatest percent of mass saving. The present figure shows that the preferable thickness of AD85 ceramic tile at $V_{1}=1000 \mathrm{~m} / \mathrm{s}$ is $20 \mathrm{~mm}$ which gives a mass saving of $40.5 \%$. The $30 \mathrm{~mm}$-thick AD85 ceramic saves masses of $41.6 \%$ and $35.5 \%$ at $V_{i}=1200$ and $1800 \mathrm{~m} / \mathrm{s}$, respectively.

Figure 14 plots the change of mass saving in percent with thickness of $\mathrm{SiC}$ ceramic at different impact velocities, respectively. For $V_{i}=1000 \mathrm{~m} / \mathrm{s}$, the mass saving in percent does not have a trend with increasing ceramic thickness. This is due to the decrease in residual penetration depth into thick steel back plate with increasing ceramic thickness until it reaches zero at $\mathrm{H}_{\mathrm{c}_{0}}=$ $30 \mathrm{~mm}$. For $\mathrm{H}_{\mathrm{co}_{0}}>30 \mathrm{~mm}$, the ceramic thickness has a mass greater than that corresponding to the penetration depth in steel back plate. The model predicts the preferable thicknesses of ceramic facing the thick steel back plate at $V_{i}=1250,1500$ and $1750 \mathrm{~m} / \mathrm{s}$; these thicknesses are 20,30 and $40 \mathrm{~mm}$ which give mass savings of $43.7,51.3$ and 53.1 , respectively.

Figure 15 shows the predicted change of limit areal density with impact velocity for the different types of ceramic. For each impact velocity, the limit areal density for each ceramic type is calculated by multiplying the limit thickness of a ceramic type at this velocity into its density. It is seen from the figure that both the $\mathrm{Ti} \mathrm{B}_{2}$ and $\mathrm{B}_{4} \mathrm{C}$ ceramic types have the minimum areal densities at the considered impact velocity range. Moreover, Figure 16 predicts that both types of ceramic have the highest limit ballistic efficiency compared with the other ceramic types. Therefore, it is recommend to use the $\mathrm{Ti}_{2}$ and $\mathrm{B}_{4} \mathrm{C}$ ceramic types for constructing the bilayered lightweight targets.

\section{CONCLUSIONS}

- The present analytical model has good predictive capabilities when the flow stress of thick metallic plate is dependent on its degree of deformation rate and that of ceramic is taken as $(0.64 \pm 0.016) \mathrm{HEL}$.

- The ballistic efficiency of ceramic types increases with its flow stress and impact velocity except for $\mathrm{B}_{4} \mathrm{C}$ ceramic type; this may be due to the density of such a ceramic, which is low in comparison with the other types of ceramic.

- The sope of $Z$ of $/ H_{1}$ for alumina ceramic is constant and independent of impact velocity and ceramic thickness. However, different slopes of $Z_{\text {res }} / H_{\text {co }}$ are obtained for other types of ceramic. 
- The present model could predict the thickness of ceramic tile that gives the maximum percent of mass saving.

- The areal densities of $B_{4} C$ and $T i B_{2}$ ceramics are minimum and they could be used to construct the bi-layered lightweight armors.

\section{REFERENCES}

1. Riad, A. M., "Modeling Penetration of Ceramic/Metal Lightweight Armours by Small and Medium Caliber Projectiles", $8^{\text {th }}$ Int. Conf. on ASAT, Vol. 1, pp. 289-309, Cairo (1999).

2. Reaugh, J. E., Holt, M. L., Wilkins, M. L., Cunningham, B. J., Hord, B. L. and Kusbov, A. S., "Impact Studies of Five Ceramic Materials and Pyrex", Int. J. Impact Engng., Vol. 23, pp. 771-782 (1999).

3. Wilkins, M. L., "Third Progress Report of Light Armor Program", Lawrence Radiation Laboratory, University of California, U.S.A., UCRL- 50460, July (1968).

4. Rosenberg, $Z$. and Yeshurun, $Y$., "The Relation between Ballistic Efficiency and Compressive Strength of Ceramic Tiles", Int. J. Impact Engng., Vol. 7, No. 3, pp. 357-362 (1988).

5. Woodward, R. L., Gooch, W. A., JR. O'Donnell, R. G., Perciballi, W. J., Baxter, B. J. and Pattie, S. D., "A Study of Fragmentation in Ballistic Impact of Ceramics", Int. J. Impact Engng., Vol. 15, No. 5, pp. 605-618 (1994).

6. Rosenberg, $Z$. and Tsaliah, J., "Applying Tate's Model for the Interaction of Long Rod Projectiles with Ceramic Targets", Int. J. Impact Engng., Vol. 9, No. 2, pp. 247-251 (1990).

7. Woodward, R. L., "A Simple One-Dimensional Approach to Modeling Ceramic Composite Armor Defeat", Int. J. Impact Engng., Vol. 9, No. 4, pp. 455-474 (1990).

8. Orphal, D. L. and Franzen, R. R., "Penetration of Confined Silicon Carbide Targets by

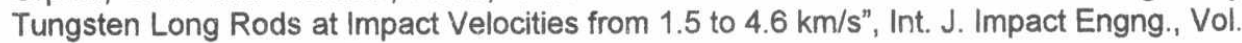
19, No. 1, pp. 1-13 (1997).

9. Orphal, D. L., Franzen, R. R., Charters, A. C., Menna, T. L. and Piekutowski, A. J., "Penetration of Confined Boron Carbide Targets by Tungsten Long Rods at Impact Velocities from 1.5 to $5 \mathrm{~km} / \mathrm{s}^{\prime}$, Int. J. Impact Engng., Vol. 19, No. 1, pp. 15-29 (1997).

10. Rosenberg, Z., Dekel, E., Hohler, V., Stilp, A. J. and Weber, K., "Hypervelocity Penetration of Tungsten Alloy Rods into Ceramic Tiles: Experiments and 2-D Simulations", Int. J. Impact Engng., Vol. 20, pp. 675-683 (1997).

11. Tate, A., "Theory of the Deceleration of Long Rods After Impact", J. Mech. Phys. Solids, Vol. 15, pp. 387-399 (1967).

12. Tate, A., "Further Results in the Theory of Long Rod Penetration", J. Mech. Phys. Solids, Vol. 17, pp. 141-169 (1969).

13. Alekseevskii, P., "Penetration of a Rod into a Target at High Velocity", Combustion, Explosion and Shock Waves, No. 2., pp. 63-66 (1966).

14. Zaera, R., Galvez, F., Rodriguez, J. and Sanchez-Galvez, V., "Design of Ceramic-Metal Armors Against Medium Caliber Projectiles", 17 th Int. Symp. on Ballistics, Midrand, South Africa, March 23-27 (1998).

15. Zaera, R. and Sanchez-Galvez, V., "Analytical Modeling of Normal and Oblique Ballistic Impact on Ceramic/Metal Lightweight Armors", Int. J. Impact Engng., Vol. 21, No. 3, pp. 133-148 (1998).

16. R. F. Recht, "Taylor Ballistic Impact Modeling Applied to Deformation and Mass Loss Determination", Int. J. Engng. Sci., Vol. 16, pp. 809-827 (1978).

17. Riad A.M., "Impact and Penetration of Full Scale and Subscale Long Rods into SemiInfinite Metallic Targets", Proc. $10^{\text {th }}$ Int. Conf. on AMME, Vol. 1, pp. 329-348, Cairo, Egypt (2002). 


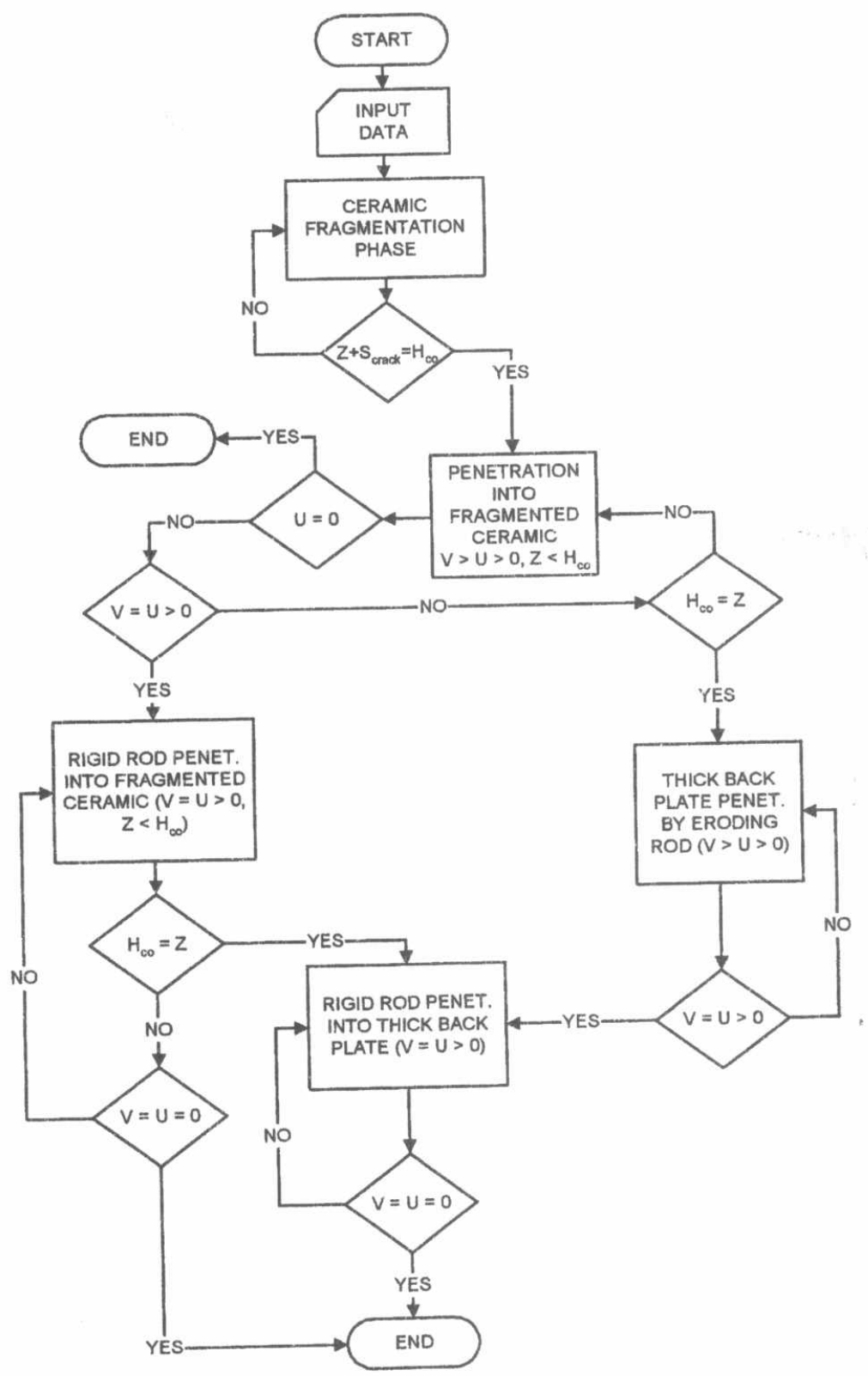

Fig. 1. A flow chart showing the main phases of the present model. 

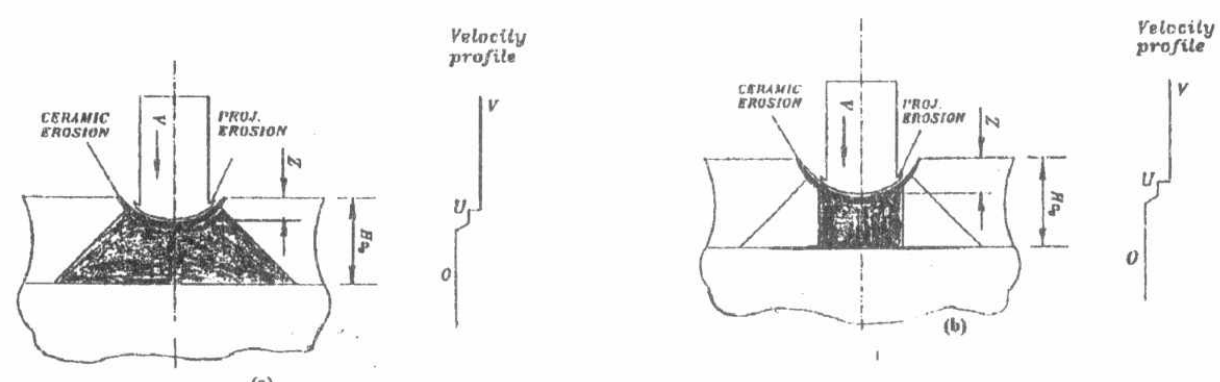

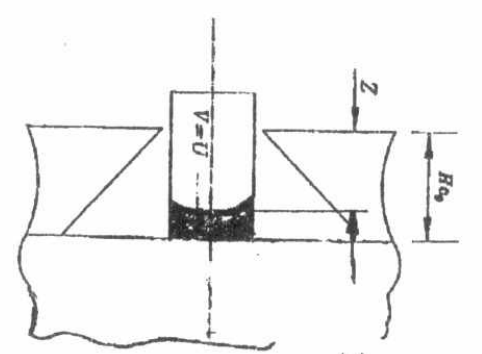

(c)

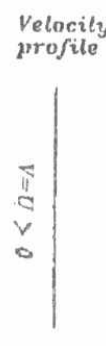

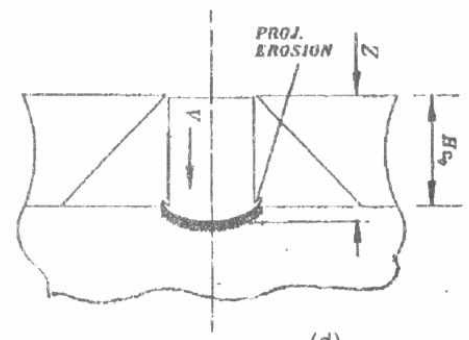

(d)
Velocity

projile

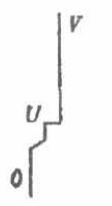

Fig. 2. A schematic of different stages of penetration process; (a) ceramic fragmentation, (b) Eroding rod penetration into fragmented ceramic, (c) rigid rod penetration into fragmented ceramic, and (d) eroding rod penetration into back plate.

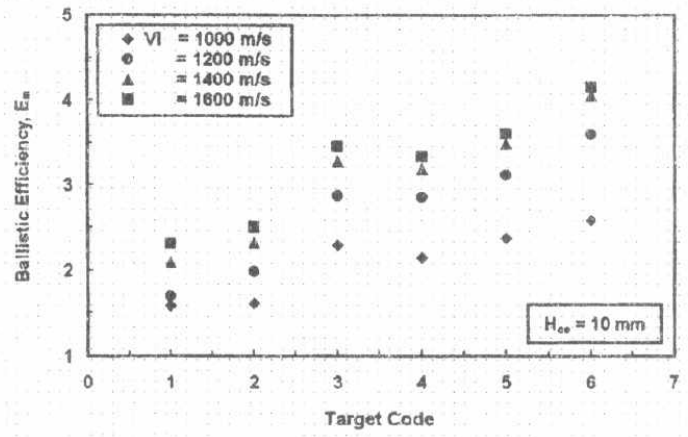

Fig. 3. Predicted change of ballistic efficiency for different ceramic types at different impact velocities.

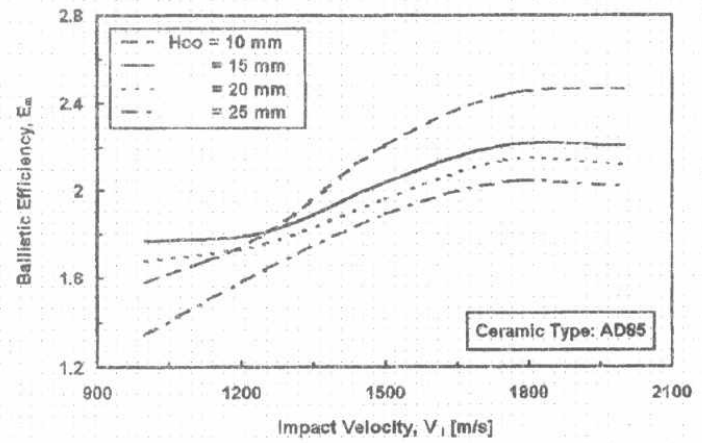

Fig. 4. Predicted change of ballistic efficiency with impact velocity for different thicknesses of AD85 ceramic. 


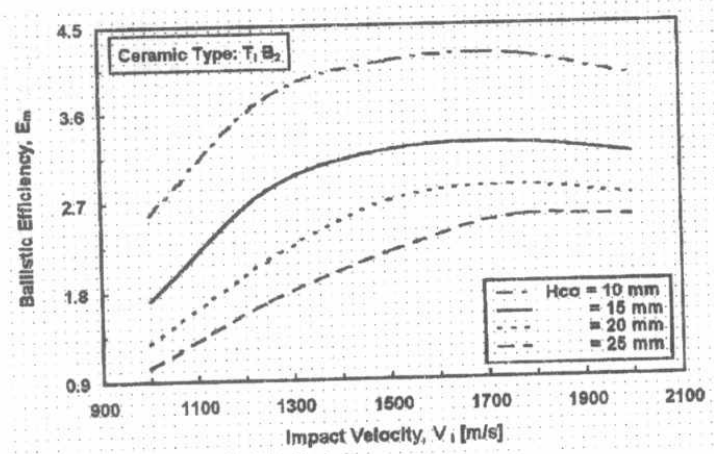

Fig. 5. Predicted change of ballistic efficiency with impact velocity for different thicknesses of $\mathrm{Ti}_{2}$ ceramic.

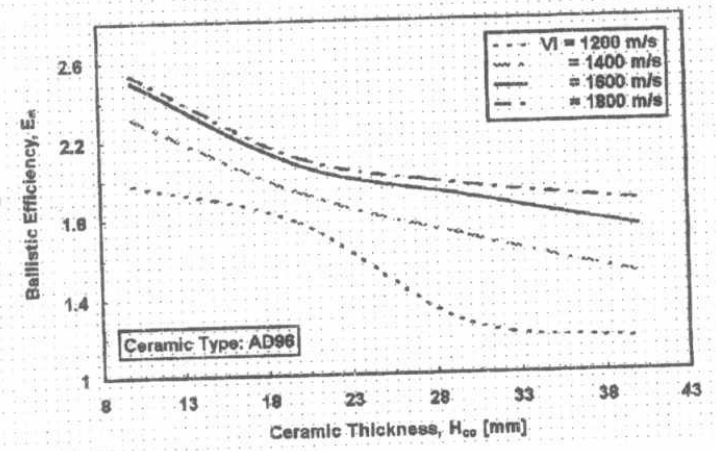

Fig. 7. Predicted change of ballistic efficiency with thickness of AD96 ceramic at different impact velocities.

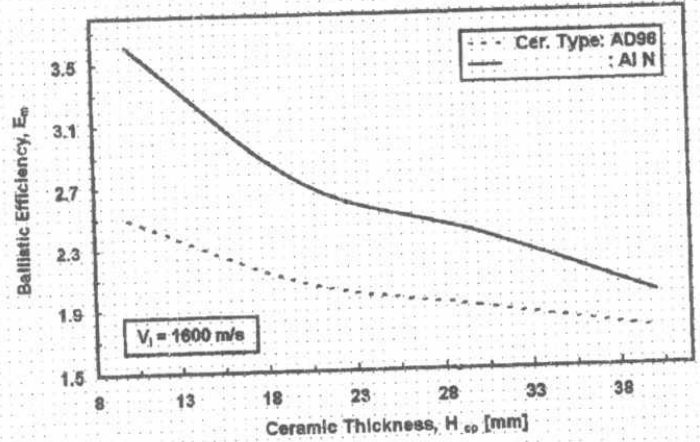

Fig. 9. Predicted change of diff. ballistic efficiency with thickness of AD96 and AL N ceramic types at $V_{i}=1600 \mathrm{~m} / \mathrm{s}$.

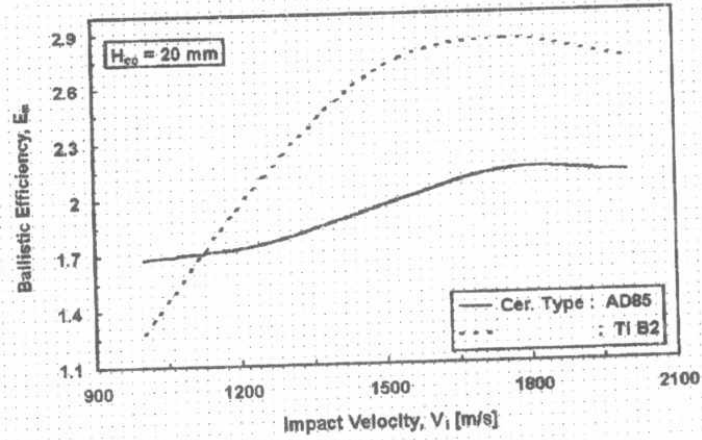

Fig. 6. Predicted change of ballistic efficiency with impact velocity for $20 \mathrm{~mm}$-thick of $\mathrm{AD} 85$ and $\mathrm{Ti}_{2}$ ceramic types.

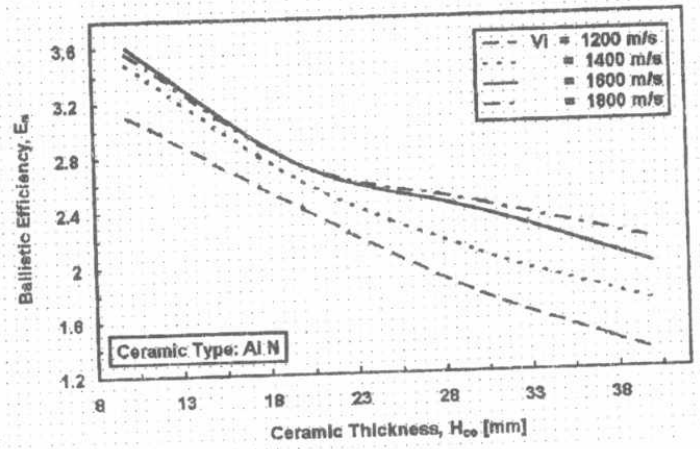

Fig. 8. Predicted change of ballistic efficiency with thickness of Al N ceramic at different impact velocities.

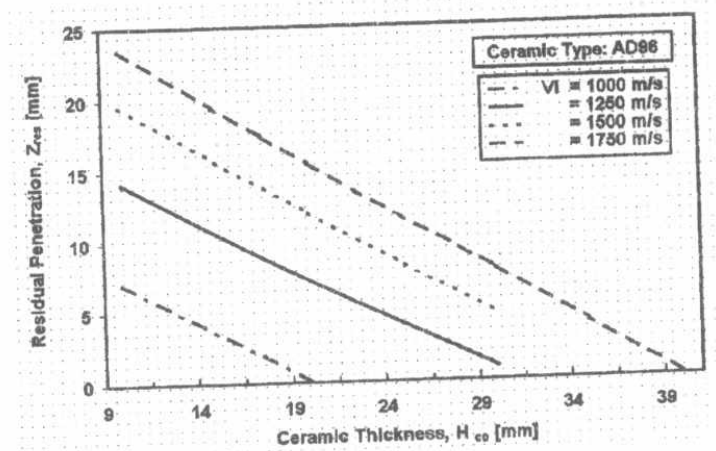

Fig. 10. Predicted change of residual penetration depth with AD96 ceramic thickness at different impact velocities. 


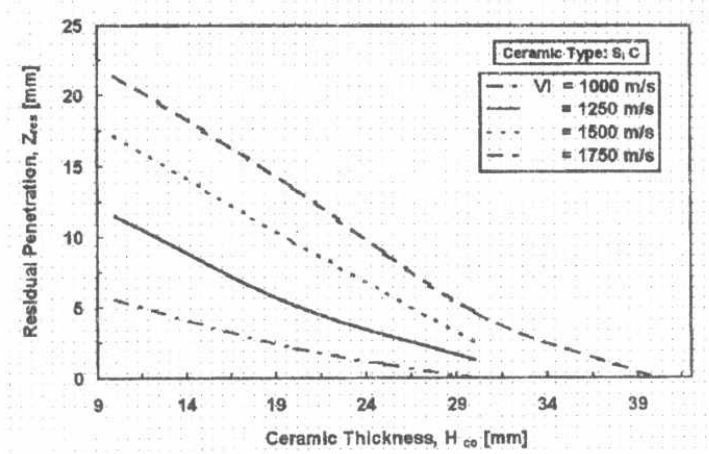

Fig. 11. Predicted change of residual penetration depth with $\mathrm{SiC}$ ceramic thickness at different impact velocities.

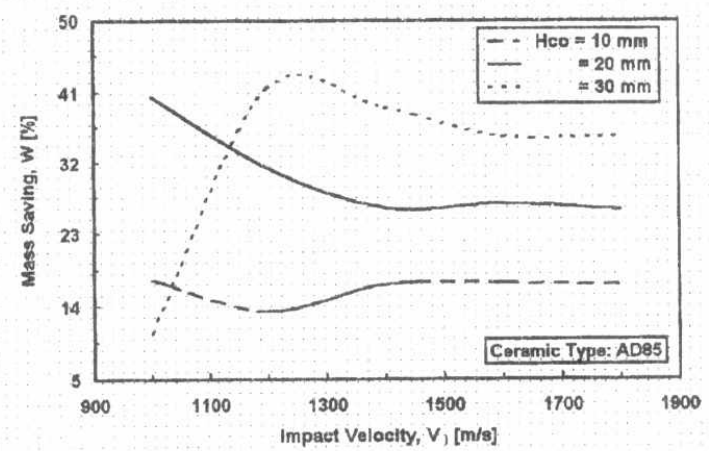

Fig. 13. Predicted percent of mass saving with impact velocity for different thicknesses of AD85 ceramic.

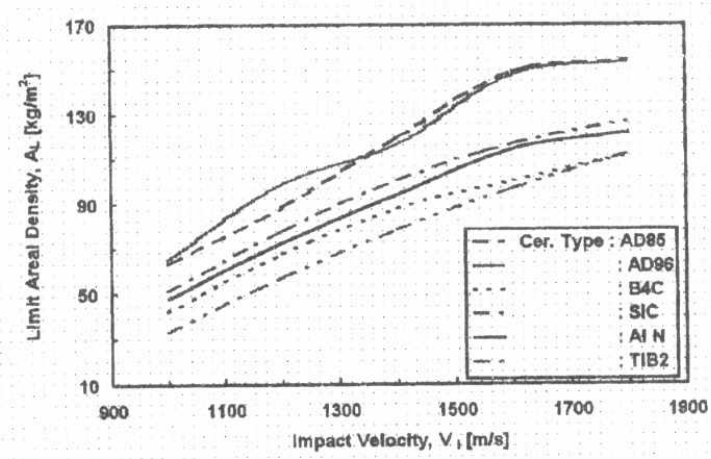

Fig. 15. Predicted change of limit areal density with impact velocity for different types of ceramic.

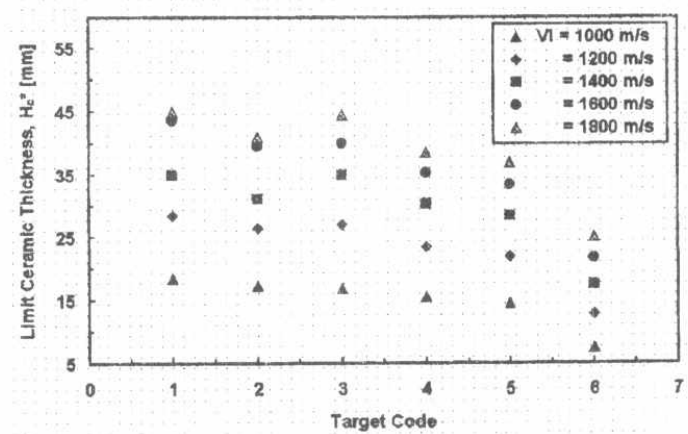

Fig. 12. Predicted change of limit ceramic thickness for different type of ceramic at different impact velocities.

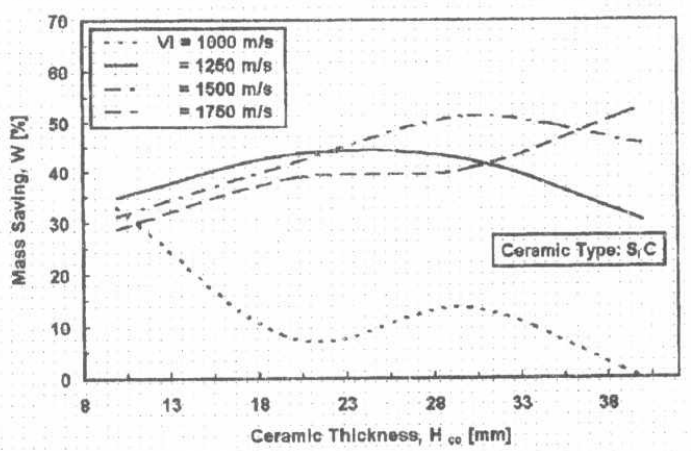

Fig. 14. Predicted percent of mass saving with $\mathrm{SiC}$ ceramic thickness at different impact velocities.

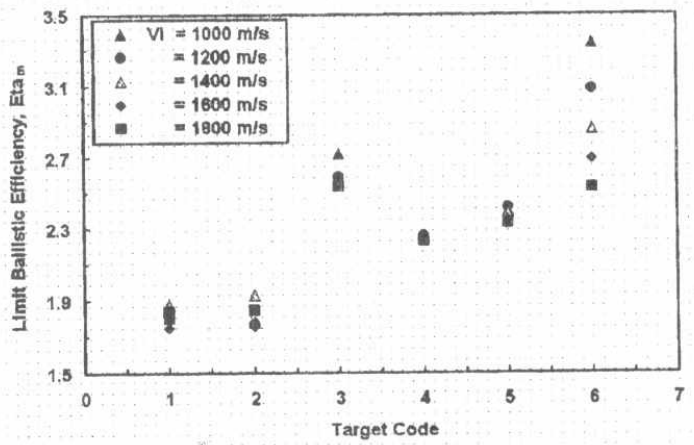

Fig. 16. Predicted change of limit ballistic mass efficiency for different types of ceramic at different impact velocities. 